\title{
INFLUENCE OF CHALCOPYRITE STRUCTURE ON THEIR LEACHING BY SODIUM NITRATE IN SULPHURIC ACID
}

\author{
Miroslav Sokić ${ }^{1 *}$, Slobodan Radosavljević ${ }^{1}$, Branislav Marković ${ }^{1}$, \\ Vladislav Matković ${ }^{1}$, Nada Štrbac ${ }^{2}$, Željko Kamberović $^{3}$, Dragana Živković ${ }^{2}$ \\ ${ }^{1}$ Institute for Technology of Nuclear and Other Mineral Raw Materials, \\ Belgrade, Serbia \\ ${ }^{2}$ University of Belgrade, Technical Faculty at Bor, Serbia \\ ${ }^{3}$ University of Belgrade, Faculty of Technology and Metallurgy, Belgrade,
} Serbia

Received 04.02.2014

Accepted 25.02.2014

\begin{abstract}
During the chalcopyrite leaching by sodium nitrate and sulfuric acid solution, leaching rate decreases with increasing the time and a part of chalcopyrite mineral grains remains in the leach residue. In chalcopyrite concentrate, $95.5 \%$ of chalcopyrite mineral occurs as in liberated grains, and the rest is in association with gangue minerals, which is very favorably from the aspect of hydrometallurgical treatment. Complex forms, like impregnations and complex intergrowths, do not exist. After experiments carried out, leaching of copper achieved $84 \%$ at temperature $80{ }^{\circ} \mathrm{C}$ and time $240 \mathrm{~min}$. In the all leach residues, $97 \%$ chalcopyrite mineral grains occur as liberated with highly corroded surfaces. Therefore, the structural assembly of chalcopyrite grains is favorable and no reason to reduce the leaching rate in the final stage of reaction. Reason for this is elemental sulfur, which was formed during the reaction, precipitated at the particle surfaces, and slowed down the leaching rate in the final stage of leaching process.

Keywords: chalcopyrite leaching, quantitative microscopic analysis, structural characteristics of mineral grains
\end{abstract}

\section{Introduction}

A complex sulphide is an association of chalcopyrite, sphalerite and galena disseminated in a pyritic matrix. Since copper, zinc and lead are valuable metals, such deposits may contain significant quantities of silver, gold, bismuth, mercury, antimony and arsenic also. Complex ores are often characterized by particulary fine intergrowth of the mineral values. For instance, chalcopyrite and sphalerite are frequently

${ }^{*}$ Corresponding author: Miroslav Sokić: m.sokic@itnms.ac.rs 
intergrown, micro-size grains of $10-20 \mu \mathrm{m}$ are being dispersed within the pyrite [1]. Sometimes it is not possible to prepare flotation concentrates of the individual minerals, but only bulk concentrates. Treatment by pyrometallurgical process is usually not attractive because large amounts of $\mathrm{SO}_{2}$ will be produced.

Hydrometallurgical process offers a great potential for treating complex sulphides and it results in improving metal recoveries and eliminates air pollution hazards.

In recent years, there has been a heightened interest in the possible application of various reagents in the hydrometallurgical processing of sulphide concentrates especially chalcopyrite concentrates. Ferric and cupric ions, oxygen, other oxidants and bacteria have been used as oxidative leaching agents of chalcopyrite in sulphate and chloride media, under atmospheric or pressure conditions [2-8].

Oxidative dissolution of a sulphide concentrate using nitrate as leaching agent in an acidic medium takes place with formation of elemental sulphur and it can be represented by one of the following chemical reactions [9-11]:

$$
\begin{aligned}
& 3 \mathrm{MeS}+2 \mathrm{NO}_{3}{ }^{-}+8 \mathrm{H}^{+}=3 \mathrm{Me}^{2+}+3 \mathrm{~S}^{0}+2 \mathrm{NO}+4 \mathrm{H}_{2} \mathrm{O} \\
& \text { or } \\
& \mathrm{MeS}+2 \mathrm{NO}_{3}{ }^{-}+4 \mathrm{H}^{+}=\mathrm{Me}^{2+}+\mathrm{S}^{0}+2 \mathrm{NO}_{2}+2 \mathrm{H}_{2} \mathrm{O}
\end{aligned}
$$

The rate of the reaction is controlled by a surface chemical reaction during the initial stages of the reaction but change into a diffusion controlled mechanism towards the end of the reaction.

The aim of the research reported in this paper was to investigate the structural characteristics of chalcopyrite grains on their leaching by sulphuric acid solution in the presence of sodium nitrate.

\section{Method for characterization}

In this paper, chemical, XRD and qualitative and quantitative microscopic analysis were used to determine the characteristics of the samples of complex concentrate and leach residue.

The content of copper, zinc, lead and iron in chalcopyrite and leach residues were determined by the atomic-absorption spectrophotometer (AAS) Perkin Elmer model ANALYST 300. The samples were prepared by dissolving in mineral acids to determine the content of copper, zinc, lead, iron and sulfur in them to AAS.

The phase composition of chalcopyrite concentrate and solid residues was determined by X-ray analysis using diffractometer PHILIPS PW-1710.

Quantitative microscopic investigation was performed in reflected light on Carl Zeiss-Jena, JENAPOL-U microscope by parallel profile method (interval $1 \mathrm{~mm}$ ). Objective magnification was from 10 to $50 \mathrm{x}$. The surface of observed grain is determined using OZARIA software and system for microphotography [12]. Tailing minerals were not determined individually but generally.

Structural characteristics of aggregates are divided in five motifs:

1. Liberated grains (self-determining mineral grains with some $100 \%$ visible surfaces).

2. Mineral grains with inclusions (the observed mineral which contains some other mineral species with maximum $10-30 \%$ of surface, mostly inclusions). 
3. Impregnations (the observed mineral which contains some other mineral species with maximum $70-90 \%$ of surface).

4. Simple intergrowths (the observed mineral is grown to some different mineral where its surface is some $30-70 \%$, mostly exsolution).

5. Complex intergrowths (the observed mineral is grown to several minerals where its surface is some $10-50 \%$, mostly multiple intergrowths, and exsolution).

Measured grain areas were edited by QUAMAS software in two ways: i) over specific density and, ii) chemical analyses of obsereved minerals [12].

\section{Results and discusion}

The chalcopyrite concentrate enriched during the flotation of a $\mathrm{CuFeS}_{2}-\mathrm{PbS}-\mathrm{ZnS}$ polymetallic ore in the "Rudnik" flotation plant (Rudnik - Serbia) was used. Four particle size fractions were obtained by wet sieving. The chemical analysis of each size fraction is presented in Table 1.

Table 1. Grain sizing and chemical composition of chalcopyrite concentrate

\begin{tabular}{lrcccc}
\hline Particle & size & \multirow{2}{*}{ Mass $\%$} & \multicolumn{2}{c}{ Element $(\%)$} & \\
\cline { 3 - 6 } & & $\mathrm{Cu}$ & $\mathrm{Fe}$ & $\mathrm{Zn}$ & $\mathrm{Pb}$ \\
\hline+75 & 7.32 & 23.38 & 22.25 & 3.43 & 4.08 \\
$-75+50$ & 21.15 & 26.55 & 24.43 & 4.28 & 1.70 \\
$-50+37$ & 5.18 & 26.95 & 24.75 & 4.36 & 1.85 \\
-37 & 66.35 & 27.08 & 25.12 & 4.15 & 2.28 \\
\hline
\end{tabular}

X-ray diffraction (XRD) analysis was used for the phase fraction determination in the chalcopyrite concentrate; the result is shown in Figure 1. The concentrate contains mainly chalcopyrite with small amounts of sphalerite.

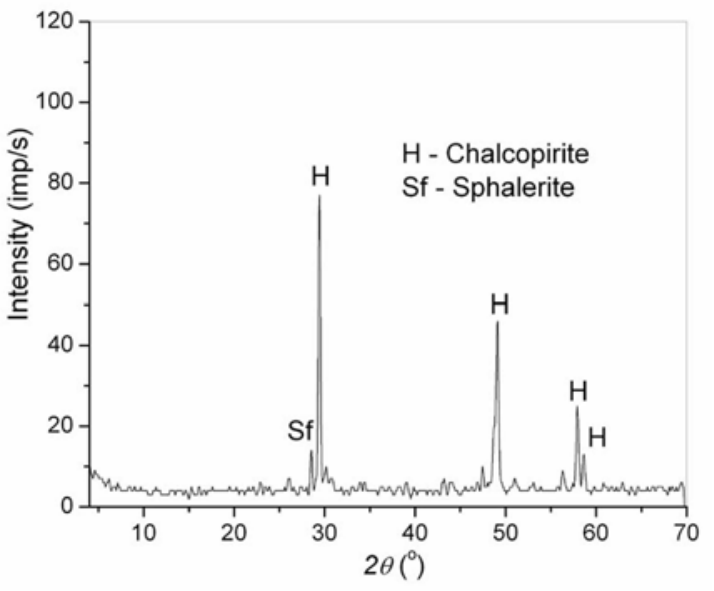

Figure 1. X-ray recordings of chalcopyrite concentrate

The mineralogical qualitative and quantitative analysis of - $37 \mu \mathrm{m}$ chalcopyrite concentrate fraction was realized using a reflected light microscopy and were given in Table 2. Gangue minerals are: quartz, silicates, and carbonates. The correction of 
quantitative mineralogical analysis was obtained through the chemical analysis of $\mathrm{Cu}$, $\mathrm{Zn}$ and $\mathrm{Pb}$. Total sulphides content in the sample is $88.5 \%$, and occurrence of the free sulphide grains is about $91 \%$. Ratio between sulfides, oxides and gangue minerals in the sample is shown in Fig. 2.

Table 2. Mineral composition of chalcopyrite concentrate

\begin{tabular}{lr}
\hline Mineral & Mass \% \\
\hline Chalcopyrite & 78.247 \\
Sphalerite & 6.249 \\
Galena & 2.633 \\
Pyrrhotite & 1.161 \\
Pyrite & 0.099 \\
Arsenopyrite & 0.211 \\
Covellite & 0.081 \\
Native bismuth & 0.031 \\
Limonite & 0.118 \\
Gangue & 11.170 \\
Total: & \\
\hline
\end{tabular}

Figure 2. The ratio of sulfides, oxides and gangue minerals in chalcopyrite concentrate $(w t \%)$

Structural characteristics of chalcopyrite aggregates are shown in Figure 3. Chalcopyrite occurrence of the liberated sulphide grains is $95.5 \%$. The rest mineral grains of chalcopyrite are mostly in a form of inclusions and simple intergrowths.

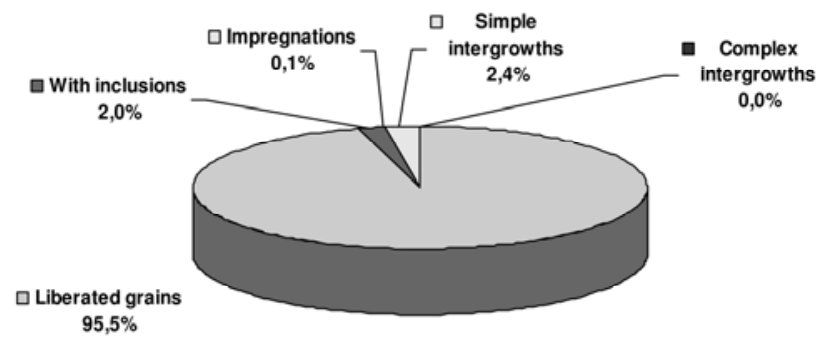

Figure 3: Structural characteristics of chalcopyrite aggregates in the chalcopyrite concentrate 
A microphotograph of the sample is shown in Figure 4. The presence of chalcopyrite and small amounts of sphalerite, which, in this case, fused with chalcopyrite, was confirmed.

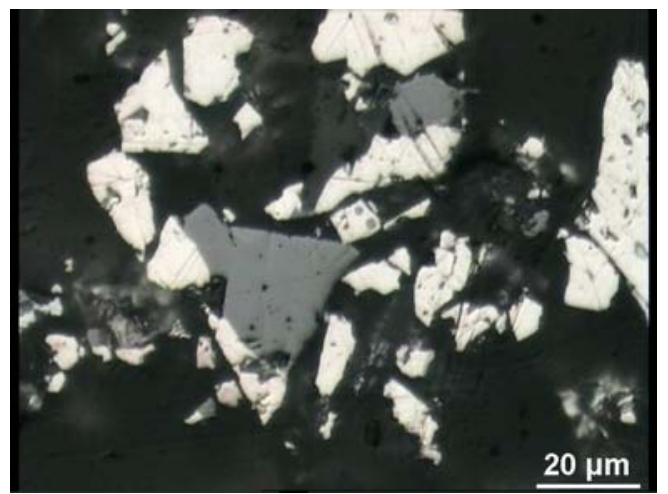

Figure 4. Simple intergrowth sphalerite-chalcopyrite, reflected light, in air, IIN.

Chalcopyrite leaching tests included the investigation of the influence of temperature and leaching time, the solid-liquid ratio, stirring speed, acid and nitrate concentration on the leaching rate and determination of their optimal values. The leaching of copper achieved $84 \%$ at temperature $80{ }^{\circ} \mathrm{C}$ and time $240 \mathrm{~min}$. It was observed that during leaching after a certain time there was a significant decrease of leaching rate and chalcopyrite remained in the solid residues. In order to explain the decrease in leaching rate in the final stage, characterization of leach residue was performed and presented.

The leach residue, obtained at $80^{\circ} \mathrm{C}$ under the following conditions: stirring speed $300 \mathrm{rpm}, 1.5 \mathrm{M} \mathrm{H}_{2} \mathrm{SO}_{4}, 0.6 \mathrm{M} \mathrm{NaNO}_{3}, 20 \mathrm{~g}$ concentrate $/ 1.2 \mathrm{dm}^{3}$ and $240 \mathrm{~min}$, was chosen for X-ray and qualitative and quantitative mineralogical analyses.

The phases identified by XRD were elemental sulphur and chalcopyrite (Fig. 5), which confirms the expectation that the elemental sulphur is formed during leaching.

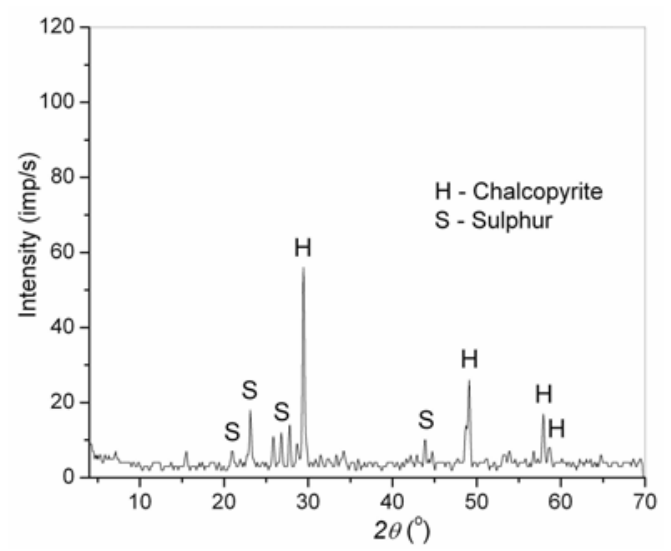

Figure 5: $X$-ray recordings of leach residue: $80^{\circ} \mathrm{C}, 240 \mathrm{~min}$. 
Qualitative and quantitative mineralogical analyses using light microscopy of the complete sample of leach residue is shown in Table 3. Total sulphides content in the sample is $61.7 \%$, and occurrence of the free sulphide grains is about $95 \%$. Ratio between sulfides, oxides and gangue minerals (quartz, sulphur and anglesite) in the sample is shown in Fig. 6. Structural characteristics of chalcopyrite aggregates in the residue are shown in Figure 7. Chalcopyrite occurrence of the liberated sulphide grains is $97.2 \%$.

Table 3: Mineral composition of leach residue

\begin{tabular}{lr}
\hline Mineral & Mass \% \\
\hline Chalcopyrite & 61.002 \\
Sphalerite & 0.222 \\
Galena & $<0.001$ \\
Pyrrhotite & 0.443 \\
Anglesite & 5.005 \\
Sulphur & 26.442 \\
Gangue & 6.886 \\
Total: & 100.000 \\
\hline
\end{tabular}

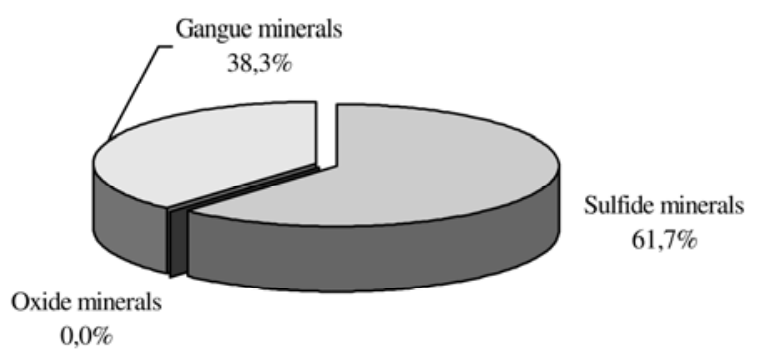

Figure 6. The ratio of sulfides, oxides and gangue minerals in leach residue (in wt \%)

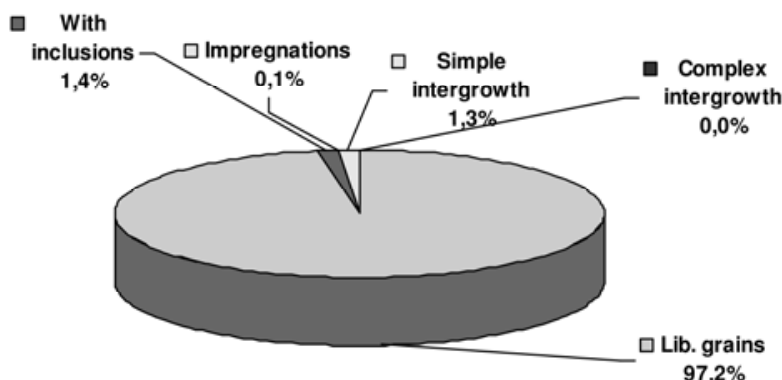

Figure 7: Structural characteristics of chalcopyrite aggregates in the leach residue 
A microphotograph of the leach residue sample is shown in Figure 8, in which can be observed the highly corroded chalcopyrite grains cemented by elemental sulphur.

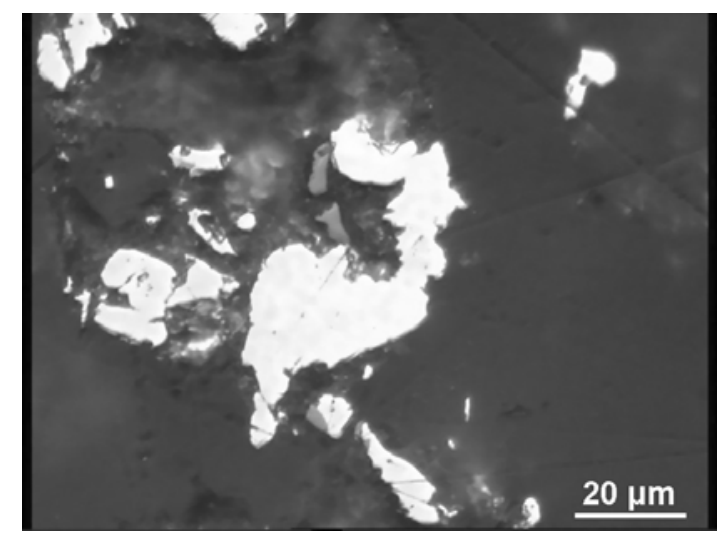

Figure 8. Corroded chalcopyrite grains cemented by elemental sulphur

The structural assembly of chalcopyrite grains in the leach residue is favorable and no reason to reduce the leaching rate in the final stage of reaction. Reason for this is elemental sulfur, which was precipitated at the particle surfaces during the leaching.

\section{Conclusion}

During the chalcopyrite leaching by sodium nitrate and sulfuric acid solution, leaching rate decreases with increasing the time and a part of chalcopyrite mineral grains remains in the leach residue. The chemical, XRD and qualitative and quantitative mineralogical analyses were used for the characterization of the chalcopyrite concentrate and leach residue. In chalcopyrite concentrate, $95.5 \%$ of chalcopyrite mineral occurs as in liberated grains, and the rest is in association with gangue minerals. In the leach residue, $97 \%$ chalcopyrite mineral grains occur as liberated with highly corroded surfaces. Therefore, the structural assembly of chalcopyrite grains in the leach residue no reason for reduce the leaching rate in the final stage of reaction. The XRD and qualitative and quantitative mineralogical analyses confirmed formation of elemental sulphur, precipitated at the particle surfaces. The leaching rate in the final stage of leaching is controlled of the lixiviant diffusion through the sulphur layer, which is formed as the reaction product during the leaching.

Acknowledgement: The authors of this paper acknowledge the financial support of Ministry of Education, Science and Technological Development of the Republic of Serbia under the projects TR34023 and TR34033.

\section{References}

[1] R. Vračar, L. Šaljić, M. Sokić, V. Matković, S. Radosavljević, Scand. J. Metall. 32, 6 (2003) 289-295.

[2] H. R. Watling, Hydrometallurgy 140 (2013) 163-180. 
[3] Y. Li, N. Kawashima, J. Li, A. P. Chandra, A. R. Gerson, Adv. Colloid Interface Sci. 197-198 (2013) 1-32.

[4] S. Prasad, B. Pandey, Miner. Eng. 11 (1998) 763-781.

[5] D. Dreisinger, Hydrometallurgy 83 (2006) 10-20.

[6] R. Hackl, D. Dreisinger, E. Peters, J. King, Hydrometallurgy 39 (1995) 25-48.

[7] R. McDonald, D. Muir, Hydrometallurgy 86 (2007) 191-205.

[8] S. Aydogan, G. Ucar, M. Canbazoglu, Hydrometallurgy 81 (2006) 45-51.

[9] R. Bredenhann, C. Van Vuuren, Miner. Eng. 12 (1999) 687-692.

[10] M. Sokić, B. Marković, D. Živković, Hydrometallurgy 95 (2009) 273-279.

[11] M. Sokić, B. Marković, Matković, D. Živković, N. Štrbac, J. Stojanović, J. Min. Metall. Sect. B. 48 (2) B (2012) 185-195.

[12] S. Radosavljević, J. Stojanović, V. Kašić, In: Proceedings of $20^{\text {th }}$ International Serbian Symposium on Mineral Processing, Ed.: Andrić Lj., Technical Faculty at Bor, Serbia, 2006, p.8-12. 